\title{
Uma análise histórica sobre a seleção natural: de Darwin-Wallace à síntese estendida da Evolução
}

\author{
A historical analysis of natural selection: from Darwin-Wallace to the \\ Evolution extended synthesis
}

Mariane Tavares da SILVA ${ }^{1}$

Charles Morphy D. SANTOS²

\section{Resumo}

Evolucionistas antes de Darwin e Wallace já tinham mencionado o mecanismo da seleção natural. Para Darwin, a variação existe em larga escala entre populações e ela está disponível para a ação da seleção natural. Parte dessa variação beneficia seus portadores na luta pela sobrevivência. Wallace chegou a conclusões semelhantes quase ao mesmo tempo. A seleção natural como mecanismo de mudança evolutiva foi universalmente adotada após a Síntese Moderna (1930-1940). Nos últimos cinquenta anos, entretanto, outros mecanismos e processos evolutivos foram descobertos. Hoje em dia, é quase consenso que a seleção natural não é suficiente para explicar a evolução biológica. Atualmente, a necessidade de uma significativa extensão da teoria evolutiva, em algo como uma Síntese Estendida, é ponto principal de discussão. Em tal teoria, a seleção natural deixa de ter um papel criativo uma vez que a variação é limitada por outros processos que não a seleção. O objetivo do presente artigo é estabelecer o papel da seleção natural em três momentos distintos da história da biologia evolutiva, de Darwin até a Síntese Estendida.

Palavras-chave: Darwin, Evolução, Seleção Natural, Síntese Estendida, Wallace.

\section{Abstract}

Evolutionists before Darwin and Wallace had already mentioned the mechanism of natural selection. For Darwin, there is variation on large scale among biological populations and it is available for the action of natural selection. Some of the variation benefits their bearers in the struggle for survival. Wallace came to similar conclusions almost at the same time. Natural selection as the mechanism of evolutionary change was universally adopted after the Modern Synthesis (1930-1940). In the last fifty years, however, other evolutionary mechanisms and processes have been discovered. Nowadays, it is almost a consensus that natural selection is not enough to explain biological evolution. Currently, the need for a significant extension of the evolutionary theory, in a sort of Extended Synthesis, is a main point of discussion. In such theory, natural selection has no longer a creative role since processes other than selection limit variation. The aim of the present paper is to establish the role of natural selection in three different moments in the history of evolutionary biology, from Darwin to the Extended Synthesis.

Keywords: Darwin; Evolution; Natural Selection; Extended Synthesis; Wallace.

\footnotetext{
${ }^{1}$ Universidade Federal do ABC | m.tavares88@gmail.com

${ }^{2}$ Universidade Federal do ABC | charlesmorphy@gmail.com
} 


\section{Introdução}

Seleção natural é reprodução diferencial por conta de variações na capacidade de sobrevivência das populações de uma espécie em um determinado ambiente. Esse processo pode levar ao aumento na proporção das características hereditárias vantajosas entre uma geração e a próxima. A teoria evolutiva de Darwin $(1858,1859)$ e Wallace $(1858)$ tem na seleção natural o mecanismo que explica a origem e diversificação das espécies.

Um dos primeiros naturalistas a despertar atenção sobre a possibilidade dos organismos se transformarem no tempo foi Jean Baptiste Lamarck (Bowler, 2003). No início do século XIX, ele defendia que todas as espécies, incluindo o Homo sapiens, originavam-se de outras pré-existentes. Em relação às causas dessas modificações, Lamarck atribuiu importância à ação direta das condições de vida, ao entrecruzamento das formas existentes, a lei de desenvolvimento progressivo e ao uso-e-desuso - fator que considerou a causa de todas as adaptações da natureza (Ridley, 2006).

No prefácio do On the origin of species, Darwin (1859) cita ainda outros autores que escreveram sobre a evolução das formas orgânicas por processos naturais. Entre eles, está Geoffroy Saint-Hilaire que falava em variações das espécies em torno de um mesmo tipo original e que considerava o meio ambiente como a causa principal dessas modificações. Darwin também discute brevemente os trabalhos de William Wells, que aplica um mecanismo semelhante à seleção natural para explicar as diferenças entre brancos, negros e mulatos, e Patrick Matthew, que comenta de forma nítida o poder de um principio análogo ao da seleção natural em um trabalho sobre construção naval e arboricultura (Mayr, 1982).

No presente artigo será apresentado um panorama sobre o papel da seleção natural biológica dentro de três momentos distintos da história da teoria evolutiva. Serão discutidas as concepções originais de Darwin e Wallace, a recepção e o impacto da teoria evolutiva de Darwin e Wallace até o surgimento da Teoria Sintética da Evolução ou Síntese Moderna, nas décadas de 1930 e 1940, e qual o possível papel da seleção natural dentro de uma Síntese Estendida da Evolução, que procura reunir os avanços dos últimos cinquenta anos para a compreensão da origem e diversificação orgânica.

\section{Seleção natural para Darwin e Wallace}

Darwin (1859) defende que a variação biológica existe em larga escala e está disponível para a ação da seleção natural, que por sua vez favorece os seres mais aptos na luta pela sobrevivência. As características que favoreçam esses organismos no momento em que ocorre a seleção são transmitidas para as futuras gerações, que também teriam vantagens sobre as outras variantes. Por um processo de acumulações de variações vantajosas, surgiriam organismos altamente adaptados aos seus ambientes.

Dentro desse contexto, as variedades morfológicas existentes dentro de uma mesma espécie são o substrato sobre o qual a seleção natural atua. As causas da variação seriam disponibilidade de alimento e nutrientes, clima, distribuição geográfica das populações de uma mesma espécie e isolamento geográfico. Para Darwin (1859), todas os morfotipos podem existir a priori. A seleção atuaria modificando parte por parte do organismo conforme as condições de vida que ele suporta em um processo gradual e acumulativo que levaria à adaptação dos organismos. Assim, cada perfil que um organismo apresentou no correr da história evolutiva da sua linhagem teve alguma vantagem seletiva. 
A ideia darwiniana central é que na natureza ocorre uma luta pela sobrevivência notadamente entre membros de uma mesma espécie. Estudos sobre a criação de animais domésticos e a leitura do trabalho de Malthus sobre as populações humanas levaram Darwin a desenvolver o cerne da sua teoria (Mayr, 1982; Bowler, 2003). Nela está incluída a ideia de interdependência dos seres vivos para a sua sobrevivência e capacidade de deixar descendentes. Como nascem mais indivíduos do que o número dos que poderiam sobreviver, sempre haverá uma luta pela existência, seja entre os indivíduos da mesma espécie, entre os de espécies diferentes, ou com as condições de vida de seu hábitat. A redução do número de indivíduos sempre incide sobre uma parcela da população, seja por recursos divididos pelos seus membros (competição interespecífica), seja por predação. Quando as limitações à sobrevivência são reduzidas, o decréscimo populacional diminui os fatores limitantes relacionam-se à disponibilidade de alimento, ao clima, predação, competição por polinizadores e disputas por parceiros para acasalamento.

O que Darwin denomina seleção natural é a preservação das variações favoráveis e eliminação das variações nocivas. Aquelas variações nem vantajosas e nem nocivas não serão afetadas, permanecendo como características oscilantes. Cada característica selecionada seria "testada" pelo ambiente e o indivíduo se desenvolveria em condições de vida adequadas à sua estrutura. A menor diferença entre as estruturas poderia alterar o equilíbrio natural na luta pela sobrevivência, garantindo ou não a preservação de certas variedades dentro das populações. Dentro dessa perspectiva, para que a seleção natural possa provocar mudanças evolutivas, seria preciso que as populações tivessem um grande número de indivíduos. Isso aumentaria a chance do aparecimento de variabilidade e garantiria que, caso um organismo com uma variação vantajosa fosse predado ou morto por um evento estocástico, essa variação continuaria presente na população para que a seleção atuasse.

Segundo a concepção darwiniana de seleção natural a variação dentro das populações é necessariamente aleatória, i.e., não direcional. Para Darwin, a fonte de variabilidade não seria uma força divina que ordenava a evolução dos organismos, como defendido por Asa Gray e Charles Lyell (Pigliucci, 2009).

Para explicar a manutenção das variações na descendência, Darwin, na ausência de informações sobre genética, aceitava a herança de caracteres adquiridos e o princípio do uso e desuso, conceitos anteriormente utilizados por Lamarck (Bowler, 2003). O raciocínio lamarckista de Darwin fica claro em algumas passagens do On the origin of species "(...) eu encontrei no pato doméstico que ossos da asa pesam menos e os ossos da perna pesam mais, em proporções ao esqueleto como um todo, do que ocorre com os mesmo ossos no pato selvagem, e esta mudança pode ser atribuída seguramente ao fato de que o pato doméstico voa muito menos e anda mais do que seus parentes selvagens" (Darwin, 1859, p. 38).

O princípio da seleção natural para Darwin se aplicava a todos os seres vivos, inclusive ao homem, e explicaria também a evolução das suas faculdades morais e intelectuais. Estas seriam condições modificadas a partir de rudimentos presentes nos demais vertebrados, da mesma maneira e pela ação das mesmas leis gerais das quais derivaram a sua estrutura morfológica (Carmo \& Martins, 2006).

Darwin privilegia a seleção natural como o mecanismo responsável pela maior parte da diversidade biológica, mas não desconsidera a existência de outros processos evolutivos. Ele mesmo desenvolve a ideia de seleção sexual (Darwin, 1871), diretamente relacionada à vantagem que certos indivíduos apresentam sobre outros da sua mesma espécie pela posse do sexo oposto. Quando machos e fêmeas possuem os mesmos hábitos, mas diferem na 
ornamentação e tamanho, i.e., quando há dimorfismo sexual, pode-se dizer que tais variações são resultado de seleção sexual. Geralmente a maior variabilidade existe entre machos que disputam a preferência das fêmeas - essas características serão transmitidas apenas à descendência masculina (Ridley, 2006).

O também naturalista britânico Alfred Russel Wallace chegou às mesmas conclusões que Darwin sobre a seleção natural de forma quase concomitante (Mayr, 1982; Bowler, 2003). Os relatos dos trabalhos de Darwin e Wallace foram publicados conjuntamente em 1858 (Darwin, 1858; Wallace, 1858). Ambos fizeram referência à luta pela existência, inspirados pelo trabalho de Malthus (Mayr, 2006), defendendo que, na natureza, o indivíduo mais bem adaptado sobrevive e deixa mais descendentes. Porém, os dois autores discordavam de alguns aspectos fundamentais da seleção natural.

Wallace de fato não utilizou o termo seleção natural, mas referiu-se ao mesmo processo denominado por Darwin. Em Wallace (1855), ele somente explicita que uma espécie tende a se transformar em outra, mas não deixa claro qual o mecanismo responsável por isso. Wallace defendia a ocorrência de mudanças graduais e não uma tendência à progressão, na qual a sucessão da vida no globo seguia de um grau de organização inferior para um superior.

Anos depois, Wallace (1890) discutiu a visão darwinista da teoria evolutiva sob a luz de dados coletados ao longo de trinta anos após a publicação do On the origin (Darwin, 1859). Ele propôs o seguinte cenário: os organismos vivem em perpétua luta pela sobrevivência; somente por meio da exata adaptação de sua organização ao ambiente, incluindo seus instintos e hábitos, eles podem sobreviver e produzir descendentes que ocupem o seu lugar. Para Wallace, embora em alguns casos a sobrevivência dos indivíduos decorresse mais do acaso do que da sua real superioridade, parecia claro que os sobreviventes eram mais adaptados por conta da sua "perfeita organização" - essa sobrevivência do mais apto seria equivalente à seleção natural darwiniana (Wallace, 1890).

Assim como Darwin, Wallace considerava que a luta mais severa era aquela travada por espécies muito próximas ocupando a mesma região. Ele também defendia o "princípio de utilidade", segundo o qual nenhum fato específico da natureza orgânica, nenhum órgão especial, nenhuma forma característica ou notável, nenhuma peculiaridade nos instintos ou hábitos, nenhuma relação entre espécies ou grupos de espécies pode existir se não foi alguma vez útil para os indivíduos ou raças que a possuem. Esse princípio seria garantido pela seleção natural, que fixaria tais características úteis (Wallace, 1890). Na teoria de Darwin-Wallace, as adaptações evoluem em pequenos passos a partir de órgãos, padrões de comportamento, células ou moléculas pré-existentes (Ridley, 2006).

Apesar das muitas congruências entre as teorias propostas por Darwin e Wallace, há pontos discordantes que por vezes fornecem explicações diferentes para o mesmo problema. Não se pode dizer que a teoria da seleção natural foi proposta por Darwin em coautoria com Wallace: ela foi proposta pelos dois autores independentemente, a despeito de incontestáveis semelhanças, o que permite considerar o momento inicial do evolucionismo como teoria de Darwin-Wallace. Wallace dava importância máxima e exclusiva à seleção natural como processo evolutivo (Carmo et al., 2009). Darwin não excluía a possibilidade de outros mecanismos serem importantes na evolução (Darwin, 1859).

Para Wallace (1890), a natureza moral e intelectual do homem não teria sido desenvolvida somente pela variação aleatória - independentemente da sua causa - e pela seleção natural. Segundo ele, um grande número de faculdades mentais que existentes nos selvagens ou existentes em condições rudimentares aparecem bastante desenvolvidas nas por ele chamadas "raças civilizadas". Tais características não teriam se desenvolvido por um 
processo lento e acumulativo como a seleção natural. Para Wallace, haveria uma diferença entre a origem das características físicas e mentais do homem em relação àquelas de outros animais. O propósito do mundo seria desenvolver o espírito humano em associação com o corpo. Existiria, dessa forma, um mundo invisível, o "mundo dos espíritos" (Mayr, 1982).

Wallace não era adepto de explicações por seleção sexual. As diferenças de ornamentação, estrutura e cor existentes entre machos e fêmeas seriam explicadas apenas por seleção natural. Nesse sentido, a coloração dos animais estaria relacionada à defesa ou ao reconhecimento pela própria espécie. O termo seleção sexual se restringiria aos resultados diretos da luta e combate entre os machos (Carmo et al., 2009).

Outro ponto importante na percepção de Wallace sobre os mecanismos evolutivos é que, para ele, a variação e a seleção natural superavam os efeitos do uso e desuso. Portanto, ele negou o papel desse processo e da herança dos caracteres adquiridos na teoria da evolução: os efeitos do uso e desuso seriam pequenos e não herdáveis. Wallace era simpático à teoria da "continuidade do plasma germinativo" de August Weismann (plasma germinativo seria o material responsável pela hereditariedade, contido nas células reprodutivas), cuja consequência é que quaisquer caracteres adquiridos não seriam transmitidos dos progenitores para seus descendentes (Ridley, 2006).

Como visto, as ideias de Wallace se assemelham mais àquelas presentes na Síntese Moderna da Evolução de meados do século XX (Mayr, 1982) do que às ideias originais de Darwin no On Origin of species (Darwin, 1859).

\section{A centralidade da seleção natural na Síntese Moderna}

A seleção natural como mecanismo de mudança evolutiva só foi universalmente adotada pelos biólogos após a Síntese Moderna da Evolução (1930-1940) (Mayr \& Provine, 1980; Mayr, 19822006). Isso, segundo Mayr (2006), deve-se ao fato de que a teoria evolutiva de Darwin não é monolítica. Ele dividiu o paradigma evolutivo darwiniano em cinco teorias principais (que não representam, entretanto, todas as teorias evolutivas de Darwin; faltam a seleção sexual, a pangênese, o efeito do uso e desuso e a divergência de caracteres). São elas:

Evolução: o mundo não é imutável, nem foi recentemente criado, está constantemente mudando e os organismos se transformam na dimensão do tempo;

Ancestralidade comum: todo grupo de organismos descende de um ancestral comum e todos os organismos e microrganismos tiveram uma única origem na Terra;

Multiplicação das espécies: explica a enorme diversidade orgânica. As espécies se multiplicam separando-se em espécies filhas ou florescem pelo estabelecimento de populações fundadoras, isoladas geograficamente, a partir das quais evoluem novas espécies;

Gradualismo: a mudança evolutiva ocorre pela transformação gradual da população, e não por uma mudança rápida (saltacional);

Seleção natural: a mudança evolutiva ocorre pela abundância de variação em todas as gerações. Os indivíduos que sobrevivem, devido a uma combinação bem adaptada de caracteres hereditários, originarão a próxima geração.

A maioria dos evolucionistas após 1859 - autores que tinham aceitado a primeira das teorias supracitadas (evolução) - rejeitaram pelo menos uma das outras quatro teorias de Darwin (Mayr, 2006). Eles explicavam, por exemplo, a ancestralidade comum por mecanismos Lamarckistas, finalistas ou saltacionistas (Bowler, 2003). Somente depois que as 
críticas anti-darwinianas do início do século XX foram refutadas é que a visão assumida pela Síntese Moderna foi amplamente adotada (Mayr, 2006). São exemplos dessas posturas antiDarwinianas: fisicismo, criacionismo, saltacionismo e transformismo.

Na Síntese Moderna da Evolução (Mayr \& Provine, 1980; Mayr, 1982; Mayr, 2006), a seleção natural é considerada o principal mecanismo responsável pela evolução dos organismos. Sendo assim, ela assume um papel central na teoria evolutiva e é o núcleo duro do programa de pesquisa em evolução. A seleção natural explicaria tanto a origem da diversidade biológica quanto a adaptação dos organismos à variação ambiental (Ridley, 2006). Em certo sentido, os teóricos da Síntese Moderna são mais selecionistas que o próprio Darwin já que ele nunca excluiu a possibilidade de existência de processos complementares à seleção natural (Darwin, 1859).

Em linhas gerais, para que a seleção natural ocorra, algumas condições são necessárias (Lewontin, 2010): os organismos precisam ser capazes de se reproduzir, suas características devem ser hereditárias, deve existir variação de caracteres individuais entre os membros de uma população, é necessária a ocorrência de variação da aptidão (fitness) do organismo (de acordo com o estado de um determinado atributo herdável. Por aptidão entende-se o número médio de descendentes diretos deixados por um membro médio da população).

Darwin (1859) não soube explicar a origem da variação e a natureza da herança. No início do século XX, August Weismann concluiu que o estudo da variação era a nova fronteira da biologia evolutiva (Mayr, 2006). Ele teve grande impacto no pensamento evolutivo, dando à seleção natural um papel exclusivo, ao excluir a mudança por uso e desuso e qualquer forma de herança de caracteres adquiridos. Os determinantes hereditários seriam passados de geração em geração apenas através das linhagens germinativas, não eram derivados de estruturas do corpo dos pais e eram imunes às alterações das células somáticas. Novas variações herdáveis ocorreriam através de mudanças acidentais ou induzidas pelo ambiente que afetassem a quantidade ou qualidade dos determinantes na linhagem germinativa. Era a reprodução sexual a responsável por reunir diferentes combinações de determinantes dos progenitores e produzir as diferenças herdáveis nos indivíduos (Mayr, 2006; Jablonka \& Lamb, 2005).

Weismann preparou o arcabouço para que a genética mendeliana pudesse ser incorporada à teoria evolutiva (Ridley, 2006). O mendelismo passou a ser a teoria da hereditariedade aceita a partir da década de 1920 e base da genética moderna. Apesar de ter possibilitado o resgate da teoria darwiniana, que culminaria na Síntese Moderna, o seu efeito inicial foi o oposto (Mayr \& Provine, 1980). Hugo de Vries e Willian Bateson, dois dos redescobridores dos trabalhos de Mendel, eram contra a teoria de Darwin. Pesquisando sobre a herança de grandes diferenças entre os organismos, sugeriram que a evolução ocorria por meio de macromutações herdadas geneticamente pela prole (Ridley, 2006).

A partir das ideias de Weismann, Fisher, Haldane e Wright conseguiram demonstrar que a seleção natural poderia operar com a genética mendeliana (Mayr, 1982; Ridley, 2006). Assim, estabeleceu-se a Síntese Moderna ou Teoria Sintética da Evolução (Mayr \& Provine, 1980; Mayr, 1982). Ela se tornou o paradigma da teoria evolutiva, centrada no papel preponderante da seleção natural atuando na variedade pré-existente originada a partir de mutações aleatórias e recombinações cromossômicas. A informação hereditária passaria fisicamente através da molécula de DNA dos progenitores para a sua prole (Ridley, 2006).

Para a Síntese Moderna, a seleção natural continuaria explicando tanto a evolução como a adaptação: a seleção leva à evolução em decorrência do surgimento de uma nova forma que tenha maiores taxas de sobrevivência e reprodução do que as formas vigentes, considerando-se um ambiente cambiante (Ridley, 2006). A variação surgiria como resultado 
de mutações durante a replicação do DNA e das recombinações cromossômicas na formação dos gametas. Por essa razão a variação é aleatória em relação à direção da adaptação. O surgimento de um novo genótipo recombinante não se relaciona a qualquer tendência no sentido de uma melhora adaptativa. Dada a enorme gama de fatores mutagênicos existentes, a variabilidade é amplamente difundida em populações naturais.

O surgimento de variantes mais ou menos vantajosas no que diz respeito ao seu sucesso reprodutivo corresponde à seleção natural. Esta exerce pressão sobre as características dos indivíduos e é essa pressão de seleção que leva à fixação de determinadas características na população. Tal fenômeno é conhecido como mudança da frequência genotípica nas populações, uma vez que, na concepção clássica mendeliana da relação genótipo-fenótipo, toda característica fenotípica refletiria um determinado gene (Ridley, 2006).

A despeito de ainda considerada o paradigma corrente da teoria evolutiva, hipóteses acessórias à Síntese Moderna foram desenvolvidas nos últimos cinquenta anos. Desde o neutralismo de Motoo Kimura, que descreveu como a mudança nas frequências genotípicas das populações ocorreria a partir de eventos estocásticos sem componente seletivo, sabe-se que é preciso incorporar outros mecanismos e processos além da seleção natural para explicar a origem e diversificação dos organismos. Atualmente alguns autores insistem na necessidade de uma significativa extensão da teoria evolutiva para a definição da assim chamada Síntese Estendida da Evolução (Pigliucci, 2009; Pigliucci \& Müller, 2010).

\section{Para uma Nova Síntese da Evolução}

A Síntese Estendida da Evolução (Pigliucci, 2009; Müller \& Newman, 2003; WestEberhard, 2003; Jablonka \& Lamb, 2005; Pigliucci \& Müller, 2010) defende que existem processos envolvidos da diversificação dos seres vivos que vão além da seleção natural discutida por Darwin, Wallace e pela Síntese Moderna: sistemas de herança epigenética (SHEs) (Newman \& Müller, 2001; Jablonka \& Lamb, 2005), Módulos de Padronização Dinâmica (MPDs) (Newman, 2009), plasticidade fenotípica (West-Eberhard, 2003) e emergência (Depew \& Weber 1995).

Em uma Síntese Estendida da Evolução, a seleção natural deixa de ter um papel criativo e passa a se relacionar à manutenção da variação limitada por outros processos, descritos abaixo. A variação não é mais considerada ilimitada, pois não depende somente de mutação e recombinação cromossômica. Como existem outros fatores que interferem na regulação gênica, fazendo com que mudanças fenotípicas não dependam de alterações genéticas de monta, a proporção 1:1 entre genótipo e fenótipo perde o sentido (Pigliucci, 2009).

Os Sistemas de Herança Epigenética (SHEs) consistem de processos epigenéticos que provocam efeito persistente no desenvolvimento dos seres vivos. Isso ocorre quando variações fenotípicas não provenientes de variação gênica são transmitidas para as gerações subsequentes de células ou organismos. Esses processos interferem nas redes de expressão gênica e, sendo assim, são cruciais para a evolução. Os SHEs podem ser divididos em quatro categorias, como apontam Jablonka \& Lamb (2005):

(1) Circuitos autossustentáveis (Figura 1A): possibilitam que células-filhas possam herdar padrões de atividade genética presentes nas células-mãe. Isso ocorre porque o controle da atividade genética envolve circuitos autossustentáveis de retroalimentação; 
(2) Herança estrutural (memória da forma) (Figura 1B): está relacionada com a manutenção das formas modificadas das estruturas celulares. As estruturas existentes são usadas para a formação de estruturas similares nas células filhas;

(3) Sistemas de marcação da cromatina (Figura 1C): a cromatina não é algo fixo e imutável, uma vez que as mesmas sequências de DNA podem ser "empacotadas" de maneiras diferentes em células diferentes e em épocas diferentes. A maneira como uma determinada região é empacotada determina quão acessível esse DNA fica aos fatores necessários para que ocorra a transcrição. A metilação do DNA e a marcação de proteínas que se ligam ao DNA e influenciam a atividade dos genes são exemplos desse tipo de herança;

(4) RNA de interferência (silenciamento gênico) (Figura 1D): Os RNAs de interferência levam ao silenciamento estável e herdável pelas células de genes específicos. Dependem de moléculas chamadas small interfering RNAs (siRNA), que se originam de moléculas muito maiores de RNA mensageiro com sequências e estruturas incomuns.

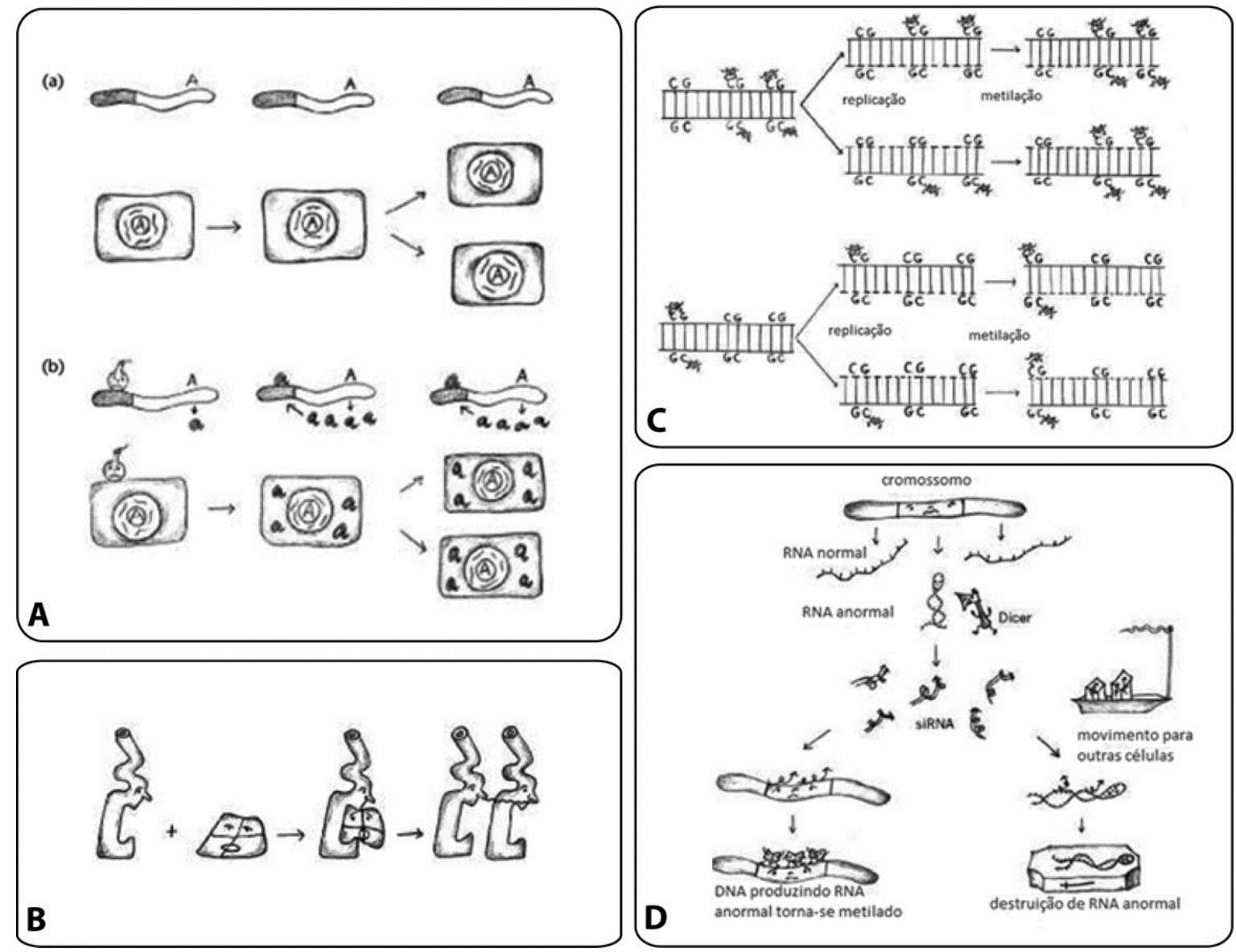

Figura 1. A. Circuitos autossustentáveis: (a) o gene A está inativo e as células-filhas herdam o estado inativo em (b), um estímulo temporário (bomba) induz a ativação da gene A e a sua produção. Como as células-filhas herdam o produto, elas também herdam o estado ativo. B. Herança estrutural: um príon aberrante (forma comprida) entra em contato com a proteína normal (forma quadrada) e a induz a mudar sua conformação, assumindo o formato aberrante. C. Replicação de dois padrões de metilação: as linhas contínuas são fitas-mães de DNA; as tracejadas são as fitas-filhas; os ícones em alguns dos Cs representam grupos metila. D. Silenciamento mediado por RNA: no alto um RNA estruturalmente anormal é produzido; esse RNA é reconhecido e desmembrado por ação enzimática.

Os fragmentos resultantes, os siRNAs, associam-se com complexos de proteínas, e, com a ajuda deles, destroem cópias do RNA anormal (à direita); eles também podem interagir com o trecho de DNA que produziu o RNA anormal e inativá-lo com uma metilação ou uma marca de proteína. Em 
alguns organismos o siRNA de alguma forma também migra para outras células (no meio à direita) (modificado de Jablonka \& Lamb, 2005).

Além dos supracitados sistemas de herança epigenética, a plasticidade fenotípica, ou plasticidade do desenvolvimento, também é importante no contexto de uma Síntese Estendida da Evolução. Ela é definida como a capacidade de resposta de um organismo ao seu ambiente durante o desenvolvimento ontogenético (West-Eberhard, 2003), que leva ao surgimento de formas distintas mesmo sem a ocorrência de alterações genéticas. Seu papel na mudança evolutiva e na adaptação foi pouco considerado na Síntese Moderna da Evolução. Uma maior plasticidade fenotípica inicial na diversificação das formas está associada a um menor controle e canalização genético-desenvolvimental destes fenótipos e, consequentemente a uma maior dependência das condições ambientais. Na figura 2 encontram-se exemplos de plasticidade fenotípica. Em cada caso o indivíduo tem modificada a sua morfologia, fisiologia, comportamento ou história de vida em resposta a uma mudança ambiental, sejam elas temporais, espaciais, bióticas ou abióticas. Tais alterações desestabilizam a homeostase e o desenvolvimento, causando um desbalanceamento entre o fenótipo e o ambiente, e diminuindo o fitness (Whitman, 2009). Atualmente, não se considera mais o organismo como agente passivo às mudanças ambientais. Em alguns casos, ele é dotado de respostas adaptativas alternativas que podem ocorrer entre gerações e ao longo de uma única geração.

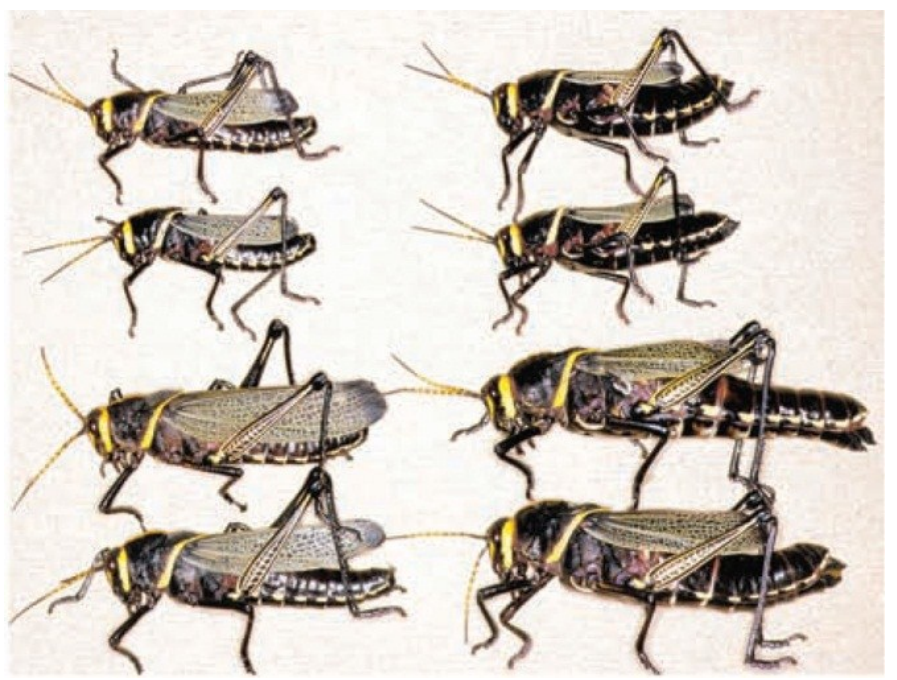

Figura 2. Exemplo de plasticidade fenotípica. A nutrição influencia fortemente o tamanho do gafanhoto Taeniopoda eques, do deserto do Arizona. Os machos estão à esquerda, as fêmeas à direita. Os quatro indivíduos abaixo estavam em um ambiente com chuvas amplas e vegetação abundante; os quatro de cima receberam pouca chuva e tinham vegetação pobre à sua disposição (modificado de Whitman, 2009).

Dentro da visão da Síntese Moderna (Mayr \& Provine, 1980; Mayr, 1982), o ambiente age após a variação ter sido produzida e tem apenas o papel de pressão de seleção. Com a plasticidade fenotípica o ambiente passa a ter um papel duplo na evolução, possibilitando a expressão de variações e atuando como pressão de seleção. O reconhecimento do papel fundamental do ambiente na expressão fenotípica é um duro golpe à visão genecentrista da biologia prevalecente em todo o século XX (Lewontin, 2010). Dentro de uma perspectiva na qual a seleção natural atua sobre o fenótipo, não se pode pensar em características isoladas, mas sim em fenótipos coletivos que geram uma resposta secundária à mudança ambiental, levando ao aumento do sucesso reprodutivo (West-Eberhard, 2003). Isso é possível porque, 
na realidade, não são os genes que evoluem, mas sim as redes de interação gênica que modulam a expressão dos genes propriamente ditos.

Levando-se em conta o papel da plasticidade fenotípica na evolução, pode-se afirmar que um único pico adaptativo, considerado a adaptação ótima à um dada pressão de seleção, não existe. O que ocorre no lugar são as paisagens adaptativas ou epigenéticas, e é nelas que a seleção natural vai agir.

Ainda no que diz respeito à origem da variação biológica os Módulos de Padronização Dinâmica (MPDs) consistem em um subconjunto dos produtos gênico daquilo que é conhecido como "kit de ferramentas genético-desenvolvimentais" (Newman \& Bhat, 2009). Os MPDs funcionam em associação com processos físicos genéricos mobilizados por eles. Dentro dessa perspectiva, os produtos gênicos controlariam parte dos parâmetros físicoquímicos como a coesão, a viscoelasticidade, difusão e a heterogeneidade espaço-temporal baseada na interação do ativador-inibidor e na dinâmica multi-estável e oscilatória. Os MPDs isolados ou em combinação uns com os outros constituiriam uma "linguagem padrão" capaz de gerar, por exemplo, os planos corporais dos animais, além das formas das estruturas e órgãos (Tabela 1). Pode-se pensar que tipos divergentes de animais modernos utilizam o mesmo conjunto de ferramentas moleculares durante o seu desenvolvimento, mas o fazem não por uma disparidade fenotípica produzida por longos períodos de tempo e sim em relação à mudança genotípica. A existência de padrões conservados de expressão desses MPDs sugere fortemente que, como discutido acima, a despeito da aleatoriedade do processo, a variação a partir da qual o mecanismo da seleção natural atua não é ilimitada.

Tabela 1. Módulos dinâmicos de padronização, seus respectivos componentes moleculares e princípios físicos, papeis na evolução e desenvolvimento, e representações esquemáticas (modificado de Newman \& Bhat, 2009).

\begin{tabular}{|c|c|c|c|c|}
\hline MPD & Moléculas & Fisica & papel na Evo-Devo & Efeito \\
\hline ADH & Caderinas & Adesão & Multicelularidade & \\
\hline LAT & Notch & $\begin{array}{l}\text { Inibição } \\
\text { lateral }\end{array}$ & $\begin{array}{l}\text { Coexistências de } \\
\text { estados celulares } \\
\text { alternativos }\end{array}$ & \\
\hline DAD & Caderinas & $\begin{array}{c}\text { Adesão } \\
\text { diferencial }\end{array}$ & $\begin{array}{l}\text { Separação de } \\
\text { fases, tecido }\end{array}$ & \\
\hline $\mathrm{POL}_{\mathbf{a}}$ & Wnt & $\begin{array}{l}\text { Anisotropia da } \\
\text { superfície } \\
\text { celular }\end{array}$ & $\begin{array}{l}\text { multicamadas } \\
\text { Mudança } \\
\text { topológica, } \\
\text { cavidades }\end{array}$ & \\
\hline $\mathrm{POL}_{p}$ & Wnt & $\begin{array}{l}\text { Anisotropia } \\
\text { da forma } \\
\text { celular }\end{array}$ & $\begin{array}{l}\text { Alongamento do } \\
\text { tecido }\end{array}$ & \\
\hline ECM & $\begin{array}{l}\text { Quitina, } \\
\text { colágeno }\end{array}$ & $\begin{array}{l}\text { Rigidez, } \\
\text { dispersão }\end{array}$ & $\begin{array}{l}\text { Solidificação do } \\
\text { tecido, elasticidade }\end{array}$ & \\
\hline OSC & Wnt + Notch & $\begin{array}{l}\text { Oscilação } \\
\text { química }\end{array}$ & $\begin{array}{l}\text { Segmentação, } \\
\text { padrão periódico }\end{array}$ & \\
\hline MOR & $\begin{array}{l}\text { TGF- } \beta \text { /BMP } \\
\text { FGF, Hh }\end{array}$ & Difusão & $\begin{array}{c}\text { Formação de } \\
\text { padrão }\end{array}$ & \\
\hline TUR & $\begin{array}{c}\text { MOR + Wnt } \\
\text { + Notch }\end{array}$ & $\begin{array}{l}\text { Estrutura de } \\
\text { dissipação }\end{array}$ & $\begin{array}{l}\text { Segmentação, } \\
\text { padrão periódico }\end{array}$ & \\
\hline
\end{tabular}


Em uma definição contemporânea, a seleção natural fica condicionada à variação existente e às condições que geram essa variação, uma vez que os processos descritos acima demonstram que, para que ocorra uma mudança nos morfotipos disponíveis, não é necessário mudança expressivas nas sequências gênicas. Nesse contexto, a contingência (Gould, 2002) perderia parte da sua influência na evolução, já que os planos corpóreos poderiam se modificar apenas em certos morfotipos por razões de restrições do desenvolvimento embrionário, que não refletem a mudança direta da frequência gênica. Assim, a seleção tem disponível para a sua ação apenas certas variantes que, por sua vez, dependem de outros fatores para o seu aparecimento. Portanto, a variabilidade prévia necessária para o processo de seleção natural é limitada. Pode-se ilustrar isso a partir das paisagens adaptativas de Wright (1932) (Figura 3).

Os processos e mecanismos supracitados são capazes de gerar diversidade em saltos e não apenas de forma gradual, alterando radicalmente o plano corpóreo dos organismos em um tempo geológico mais curto do que se imaginava. Tais mecanismos permitem estabelecer que não apenas a seleção natural é responsável pelo surgimento de novidades evolutivas, e que o seu papel mais efetivo na evolução é o refinamento e manutenção de características surgidas a partir de fontes distintas. Mecanismos como os Sistemas de Herança Epigenética e os Módulos de Padronização Dinâmica seriam responsáveis pelo aumento da disparidade morfológica entre os organismos, i.e., pela macroevolução, que corresponde à grandes mudanças nos planos corpóreos, resultando no aparecimento de clados mais inclusivos (como filos e classes). Em contrapartida, a seleção natural seria responsável pelo processo de diversificação dos organismos, uma vez que a sua influência seria mais forte no nível específico. Nessa escala, a seleção natural atuaria na microevolução (juntamente com a deriva genética, que promove a mudança da frequência gênica sem qualquer componente seletivo) através de mudanças cumulativas capazes de gerar espécies diferentes, desde que o fluxo de informações hereditárias entre as subpopulações deixe de existir.

As paisagens adaptativas de Wright (1932) (Figura 3) mostram a relação entre valor adaptativo médio e frequência gênica. A seleção natural atua no deslocamento da população ao longo da paisagem, movendo-a para o topo do pico (os picos têm valores adaptativos diferentes). Assim, a população sempre se encontra em um pico adaptativo local. Há uma variação suficiente para que qualquer organismo tenha uma chance de ter um genótipo diferente dos outros membros da sua espécie, mas apenas uma pequena fração das possíveis combinações genéticas é acessível a qualquer momento: a população é limitada a uma parte infinitesimal do campo de combinações genéticas possíveis (Wright, 1932). Se a população se encontra em um pico suficiente para garantir sua sobrevivência (e reprodução), ainda que sub-ótimo quando consideradas as soluções possíveis, ela ali permanecerá. Existem evidências empíricas de que a seleção não melhora o ajuste das populações aos seus ambientes, mesmo durante longos períodos de tempo, mas que, em vez disso, trabalha na manutenção de qualquer que seja o pico adaptativo local que a população tenha alcançado (Pigliucci, 2009).

Os vales nas paisagens adaptativas têm valores adaptativos negativos - se a espécie atinge esses vales, ela será extinta (Wright, 1932; Ridley, 2006). A mudança de pico de uma população era o que Wright chamava de problema central da evolução, pois a seleção atua no sentido de mover a população para longe dos vales. Como as populações poderiam mudar de pico adaptativo local sem passar por eles? Parte das discussões sobre paisagens adaptativas na verdade refere-se a eventos de especiação não-adaptativos ou de irradiação 
adaptativa, que são processos em que o surgimento de novas espécies não precisa ser gradual e nem ocorre pela ação da seleção natural. Neles, formam-se distintas espécies em um curto período de tempo, ocupando simultaneamente diversos nichos ecológicos (Pigliucci, 2009). Fica claro, portanto, que a seleção natural não tem grande papel na formação dos clados maiores.

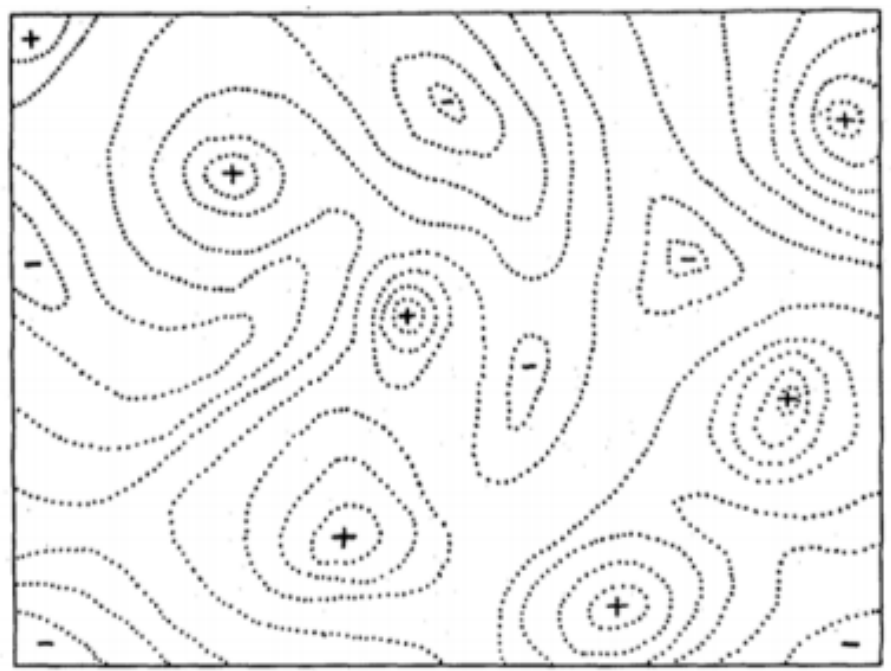

Figura 3. Representação esquemática do campo de combinação de genes em duas dimensões em vez de muitos milhares. Linhas pontilhadas representam contornos com relação a adaptabilidade (modificado de Wright, 1932).

Outro conceito interessante, às vezes confundido com o de paisagens adaptativas, é o de paisagens epigenéticas (Waddington, 1957) (Figura, 4). Na figura 4A, o patamar ligeiramente ondulado representaria o exemplo de um ovo fertilizado e o caminho que a bola segue, a rota de desenvolvimento a partir do ovo até um determinado tecido ou órgão ao final de um vale. O curso, encostas e secções transversais dos vales, é controlado por genes e suas interações.

Na figura 4B, os genes são representados por estacas e as cordas de sustentação representam as tendências físico-químicas do gene subjacentes a paisagem. Através dessa imagem, Waddington (1957) tentou mostrar que não existe uma relação simples entre um gene e seus efeitos fenotípicos. Se qualquer gene sofrer mutação, alterando a tensão em um determinado conjunto de cordas, o resultado não vai depender do gene sozinho, mas sim da interação dele com os outros indivíduos (Jablonka \& Lamb, 2005).

A maioria das variações genéticas naturais e muitas mutações induzidas experimentalmente têm pouco ou nenhum efeito sobre o fenótipo. O mesmo vale para as variações ambientais: a maioria não faz muita diferença para a aparência final do animal. 0 desenvolvimento geralmente conduz ao mesmo resultado final bem definido, apesar de variações nos genes e em circunstâncias ambientais distintas. Na terminologia de Waddington, o desenvolvimento é "canalizado" e está canalização ou tamponamento é o resultado da seleção natural para genes cujas ações e interações fazem os vales em sua paisagem epigenética profundos e com lados íngremes (Jablonka \& Lamb, 2005). Nesse sentido, a seleção atua na força de tração das cordas, fazendo com que as interações para que a paisagem se modifique precisem ser muito grandes.

Nos dois tipos de paisagem apresentados percebe-se que a seleção não age no surgimento de novidades evolutivas e sim no processo de diversificação das espécies. Os genes atuam em uma rede que é influenciada pelo ambiente e gera picos adaptativos que se modificam com o tempo. Além disso, existe a possibilidade de canalização do fenótipo 
ou mudança de pico dentro de uma mesma espécie (assim, as populações podem variar). A existência de uma paisagem com vários picos adaptativos reflete uma gama abrangente de soluções distintas para problemas adaptativos. Nesse contexto, não se pode pensar que a seleção sempre busca o ótimo, o pico adaptativo e o aumento absoluto da aptidão (fitness). O ótimo nem sempre está disponível para a ação da seleção e ela, por sua vez, acabará por premiar o sub-ótimo (Gavrilets, 1997).
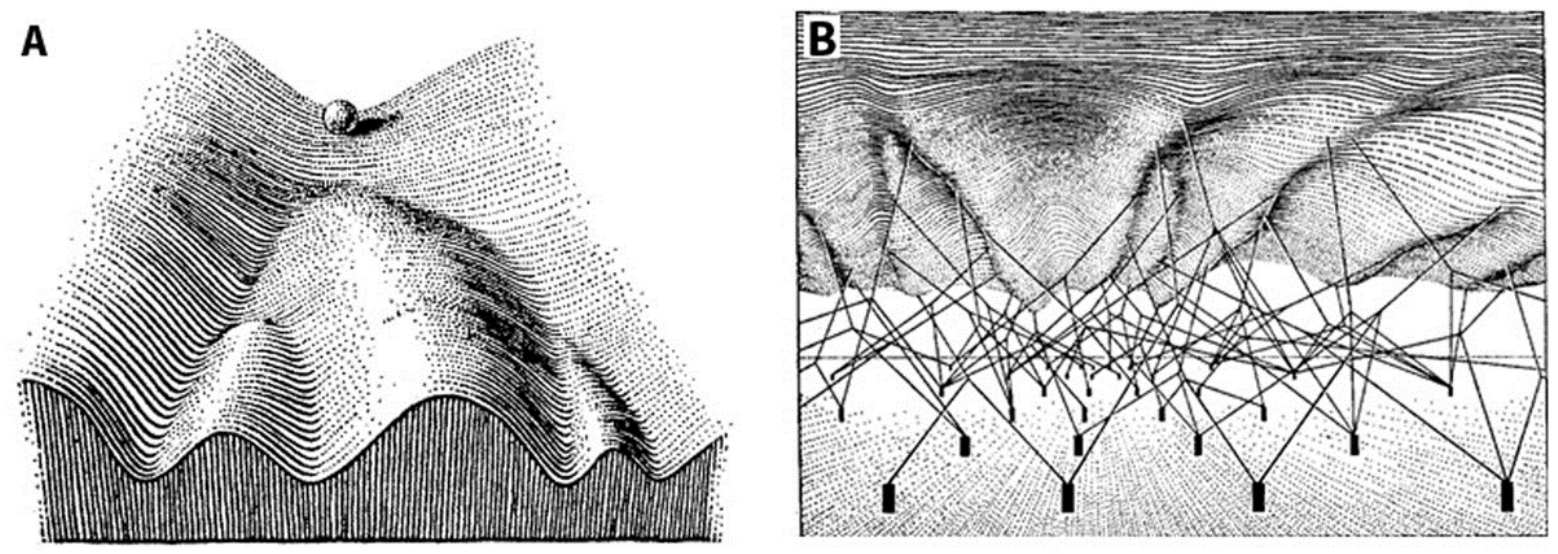

Figura 4. A. Paisagem epigenética de Waddington (modificado de Waddington, 1957). B. Interações subjacentes à paisagem epigenética (modificado de Waddington, 1957).

A definição mais aceita de adaptação seria a de um atributo ou característica que passa pelo processo de seleção (Ridley, 2006), consequentemente promovendo o aumento da aptidão dos seus portadores. Essa definição continuaria válida dentro de uma Síntese Estendida da Evolução, o que muda seria a forma como são interpretadas as adaptações. Os genes do desenvolvimento estão presentes em organismos unicelulares, ou seja, tiveram a sua origem antes do surgimento da multicelularidade propriamente dita (Carroll, 2005). Eles foram então cooptados e passaram a coordenar a vida multicelular. Dentro dessa visão contemporânea de evolução não se pode mais considerar que os genes do desenvolvimento surgem quando se origina a multicelularidade e sim antes, relacionados ao movimento citoplasmático de organismos unicelulares.

Os MPDs mostram que o surgimento da multiceluridade ocorreu por características físico-químicas dos sistemas vivos. Após o surgimento do cluster de células, a expressão gênica foi modificada. Quando surge a multicelularidade, os genes do desenvolvimento já estavam presentes em organismos unicelulares. Nesse ambiente, os genes passaram a ter uma nova função não relacionada com a regulação das cascatas gênicas mobilizadas durante a regulação do desenvolvimento em animais. Esses genes foram cooptados para uma nova função, que se mostrou vantajosa e foi mantida pela seleção natural - quando vistas a partir da regulação do desenvolvimento embrionário, os genes são exemplos de exaptação, i.e., uma adaptação biológica não surgida a partir de pressões seletivas relacionadas a sua função atual (Gould \& Vrba, 1982). No caso, a seleção tinha à sua disposição uma variação limitada - organismos unicelulares e multicelulares - e só podia agir fixando ou excluindo essas características da população. A seleção natural não fez com que a multicelularidade surgisse, só foi capaz de refiná-la (Pigliucci, 2009).

Uma analogia utilizada por Pigliucci (2009) ajuda a explicar esse cenário. Para Darwin e Wallace e na Síntese Moderna, para construir um edifício, a seleção natural precisaria coletar pedras à beira de um precipício e moldá-las até que se encaixassem perfeitamente e formassem uma estrutura sólida, com pedras mais largas na fundação, pedras menores para ornamentação e assim por diante. Aqui, quem coleta as pedras brutas e cria formas para 
que elas se encaixem no edifício em construção é a seleção natural. Porém, na Síntese Estendida, a seleção natural conta apenas com certos tipos de pedras, disponíveis em determinados momentos e durante certo tempo. Ela é capaz de decidir qual pedra utilizar, porém não determina suas formas. A seleção pode lapidar um pouco se necessário, mas o formato geral é pré-estabelecido. É nesse sentido que se pode dizer que a principal diferença que ocorre no conceito contemporâneo de seleção natural relaciona-se à variação pré-existente, que não é mais considerada ilimitada, como no paradigma anterior da Síntese Moderna.

A definição fundamental de seleção natural, que é reprodução diferencial ao longo do tempo, não é modificada na Síntese Estendida. A seleção só passa a ter um papel criativo um pouco menor. Ela ainda é um processo importante para a evolução dos organismos, mas não pode mais ser considerada o principal mecanismo evolutivo (Jablonka \& Lamb, 2005; Newman \& Bhat, 2009; Pigliucci, 2009). Essa nova interpretação vai de encontro as críticas feitas por Gould \& Lewontin (1979) ao programa adaptacionista, uma visão de evolução calcada explicitamente na seleção natural como agente capaz de levar, de forma inquestionável, ao pico adaptativo ótimo. Para esses autores, essa é uma perspectiva ingênua - nas palavras deles, panglossiana - e incompleta.

\section{Considerações finais}

A Síntese Estendida da Evolução (Pigliucci \& Müller, 2010) abrange conhecimentos advindos de inúmeras áreas da biologia importantes para a compreensão da história evolutiva dos organismos na Terra (epigenética, auto-organização, emergência, plasticidade fenotípica e módulos dinâmicos de padronização). A despeito da sua história recente - a necessidade de uma expansão da teoria evolutiva tem sido discutida apenas nos últimos 30 anos - as suas implicações dentro da biologia como um todo ainda não são completamente conhecidas. Sabe-se que esses novos conceitos e interpretações de conceitos clássicos irão alterar a visão de aspectos centrais das ciências biológicas, tais como o papel do ambiente na expressão de características fenotípicas, a origem e distribuição da variação e principalmente o conceito de herdabilidade (Jablonka \& Lamb, 2005). Sendo assim um estudo que mostre como essa área irá influenciar as sub-áreas da biologia é necessário para se estabelecer a sua abrangência e implicações reais.

O presente trabalho teve como objetivo central traçar um panorama do papel da seleção natural em diferentes momentos da história da teoria evolutiva, desde sua formalização por Darwin e Wallace até a contemporaneidade, no contexto da Síntese Estendida da Evolução. Projetos posteriores, que se concentrem no estudo da importância de cada um dos novos mecanismos descobertos na geração da diversidade biológica, são fundamentais para o aumento do escopo e do poder explanatório da teoria da evolução.

\section{Agradecimentos}

Os autores agradecem ao prof. Maurício de Carvalho Ramos (Universidade de São Paulo) pelos comentários em uma versão anterior desse manuscrito. O trabalho foi financiado pela Fundação Universidade Federal do ABC (Santo André/SP) e pelo CNPq. 


\section{Referências}

Anderson, C. Self-Organization in Relation to Several Similar Concepts: Are the Boundaries to SelfOrganization Indistinct? Biological Bulletin 202: 247-25. 2002.

Bowler, P. J. Evolution: The History of an idea, $4^{\text {th }}$ ed. University of California Press, Berkeley . 2003. 464p. ISBN 0520261283.

Carmo, V. A. \& Martins, L. A. P. Charles Darwin, Alfred Russel Wallace e a seleção natural: um estudo comparativo. Filosofia e história da Biologia. São Paulo: MackPesquisa. 1:335-350. 2006.

Carmo, V. A., Bizzo, N. \& Martins, L A. P. Alfred Russel Wallace e o princípio de seleção natural. Filosofia e história da Biologia. São Paulo: MackPesquisa. 4: 209-233. 2009.

Carroll, S.B. Infinitas formas de grande beleza: como a evolução forjou a grande quantidade de criaturas que habitam o nosso planeta. Rio de Janeiro: Jorge Zahar. Tradução. 2005 [2006]. 320 p. ISBN 8571109354.

Darwin, C. On the tendency of species to form varieties. Journal of the Linnean Society of London, 3: 45-50. 1858.

Darwin, C. A origem das espécies. $3^{\text {a }}$ ed. São Paulo. Editora Martin Claret. Tradução. 1859 [2004].

Darwin, C. The Descent of Man, and Selection in Relation to Sex. London: John Murray. 1871. 620 p. ISBN N/A.

Depew, D. \& Weber, B. Darwinism Evolving. Systems Dynamics and the Genealogy of Natural Selection. Cambridge, MA \& London: MIT Press. 1995. 601 p. ISBN 0262041456.

Gavrilets, S. Evolution and speciation on holey adaptive landscapes. Trends Ecol. Evol. 12:307-312. 1997.

Gould, S. J. The structure of evolutionary theory. Cambridge, MA. Harvard University Press. 2002.

Gould, S.J. \& Lewontin, R. The Spandrels of San Marco and the Panglossian Paradigm: A Critique of the Adaptationist Programme. Proceedings of the Royal Society of London B. 205, 581-598. 1979.

Gould, S. J. \& Vrba E. S. Exaptation-a missing term in the science of form. Paleobiology. 8: 4-15. 1982.

Jablonka, E. \& Lamb, M. Evolution in Four Dimensions: Genetic, Epigenetic, Behavioral, and Symbolic Variation in the History of Life. Cambridge, MA: MIT Press. 2005. 472 p. ISBN 9780262600699.

Lewontin, R. C. Not So Natural Selection. New York Review of Books. 2010. Disponível em: <http://www.nybooks.com/articles/archives/2010/may/27/not-so-natural-selection/>. Acesso em: 23 de nov. 2012.

Mayr, E. The Growth of Biological Thought: Diversity, Evolution, and Inheritance. Cambridge, MA: Belknap Press. 1982. 992 p. ISBN 0674364465.

Mayr, E. Uma ampla discussão: Charles Darwin e a gênese do moderno pensamento evolucionário. Ribeirão Preto, São Paulo: Editora FuNPEQ. Tradução. 2006. 224p. ISBN 8587528971.

Mayr, E. \& Provine, W.B. The Evolutionary Synthesis: Perspectives on the Unification of Biology. Cambridge: Harvard University Press. 1980. 487 p. ISBN 0674272269.

Newman, S. A., \& Bhat, R. Dynamical patterning modules: a "pattern language" for development and evolution of multicellular form. Int. J. Dev. Biol. 53: 693-705. 2009.

Newman, S. A., \& Müller G. B. Epigenetic mechanisms of character origination. In: The character concept in evolutionary biology, Wagner, G. P (ed.). Academic Press, San Diego, CA. 2001. p. 559 580. 
Pigliucci, M. An Extended Synthesis for Evolutionary Biology. Annals of the New York Academy of Sciences. 1168: 218-228. 2009.

Pigliucci, M. \& Müller, G.B. (Ed.). Evolution: the extended synthesis. MIT press. 2010. 504p. ISBN 9780262513678.

Ridley, M. Evolução. $3^{\text {a }}$ ed. Porto Alegre, Artmed. 2006. 752 p. ISBN 8536306351.

Waddington, C. H. The Strategy of the Genes. London: George Allen \& Unwin. 1957. 270 p. ISBN 9781138017313.

Wallace, A. R. Sobre a lei que regula a introdução de novas espécies. Tradução. Scientiae Studia 1(4): 531-543. 1855 [2003].

Wallace, A.R. On the tendency of varieties to depart indefinitely from the original type. Proceedings of the Linnean Society of London. 3, 53-62. 1858.

Wallace, A. R. Darwinism: an exposition of theory of natural selection with some of its applications. London: Macmillan. 2. ed. 1890. 494 p. ISBN 0231130104.

West-Eberhard, M. J. Developmental plasticity and evolution. Oxford, England: Oxford Univ. Press. 2003. 720 p. ISBN 0195122348.

Whitman, D. Phenotypic Plasticity of Insects: Mechanisms and Consequences. Science Publishers. 2009. 904 p. ISBN 9781578084234.

Wright, S. Evolution in Mendelian populations. Genetics. 16: 97-159. 1932. 